\title{
Effects of Ankylosing Spondylitis on Erectile Function
}

\author{
(D) Ibrahim Halil Erdem, ${ }^{1}$ (1) Mazhar Ortac, 2 (1) Emre Salabas ${ }^{3}$ \\ 'Department of Physical Medicine and Rehabilitation, Avcılar Murat Kölük State Hospital, Istanbul, Turkey \\ ${ }^{2}$ Department of Urology, Haseki Training and Research Hospital, Istanbul, Turkey \\ ${ }^{3}$ Department of Urology, Biruni University Faculty of Medicine, Istanbul, Turkey
}

\begin{abstract}
Objectives: Ankylosing spondylitis (AS), which is a chronic rheumatologic disorder, may be associated with erectile dysfunction (ED). This study aims to investigate the incidence of erectile dysfunction in patients with AS with a control group and to investigate the risk factors for ED.

Methods: All demographic data were recorded. Participants in both groups filled in the IIEF-5 (International Index of Erectile Function), Beck Depression Index (BDI) and Beck Anxiety Index (BAI) questionnaires, whereas patients with AS additionally filled in Bath Ankylosing Spondylitis Disease Activity Index (BASDAI), Bath Ankylosing Spondylitis Functional Index (BASFI), Bath Ankylosing Spondylitis Metrological Index (BASMI) and Ankylosing Spondylitis Quality of Life (ASQoL) questionnaires. Patients were compared concerning erectile function and predictive factors. Fifty patients with the AS diagnosis and fifty healthy males were included in this study.

Results: ED of all degrees was present in 38\% and 30\% of males in the AS group and control group, respectively, with no statistical difference. However, the mean IIEF-EF domain score of the AS group (22.3 \pm 7.0 ) was significantly lower than the control group $(25.7 \pm 4.3)(p=0.004)$. In addition, BDI and BAI scores were significantly higher in the AS group. When we have divided patients in the AS group into two, according to the presence or absence of the ED, the mean IIEF-EF domain score of patients with ED was lower than AS patients without ED. No difference was detected in both groups concerning age and the duration of the disease. Patients who had ED in the AS group had significantly higher scores in BASDAI, BASFI, depression and anxiety; however, no significant difference was detected among groups regarding BASMI scores.

Mean IIEF score was lower in patients with AS, and this had a negative correlation with BASDAI, BASFI, ASQoL, BDI and BAI scores. Conclusion: Erectile function scores were slightly lower in the AS group than the control group in our study. ED risk factors were shown as disease activity and psychological status.

Keywords: Ankylosing spondylitis; erectile function; quality of life.

Please cite this article as "Erdem IH, Ortac M, Salabas E. Effects of Ankylosing Spondylitis on Erectile Function. Med Bull Sisli Etfal Hosp 2020;54(2):188-192"
\end{abstract}

A nkylosing spondylitis (AS) is a form of chronic rheumatismal disease usually accompanied by chronic low back pain, sacroiliitis and enthesitis. The prevalence of AS is approximately $0.7 \%$, with a difference among geographic area. [1] The etiology of the disease continues to be enigmatic. Inflammation of the axial skeleton may cause a progressive vertebral deformity. AS is a young male disease with a patient population younger than 40 years old. Since AS is a chronic disease with no mortality, the patients with the disease have a normal life span. The onset and the progression of the disease coincide with the most sexually active times of the patients. Thus, possible sexual disabilities lead to an impairment of their quality of life. ${ }^{[2]}$ Musculoskeletal associated symptoms such as chronic pain, fatigue, stiffness,

Address for correspondence: Ibrahim Halil Erdem, MD. Avcilar Murat Koluk Devlet Hastanesi, Fiziksel Tip ve Rehabilitasyon Bolumu, Istanbul, Turkey Phone: +90348 8221010 E-mail: iherdem@outlook.com

Submitted Date: July 24, 2018 Accepted Date: July 27, 2018 Available Online Date: June 10, 2020

${ }^{\circ}$ Copyright 2020 by The Medical Bulletin of Sisli Etfal Hospital - Available online at www.sislietfaltip.org

OPEN ACCESS This is an open access article under the CC BY-NC license (http://creativecommons.org/licenses/by-nc/4.0/). 
depression, anxiety, negative body image severely impede physical and mental quality of life. The practitioners sometimes overlook problems such as disturbed psychology and erectile dysfunction while treating physical symptoms of the disease. ${ }^{[3]}$ Erectile dysfunction (ED) is sexual dysfunction characterized by the inability to develop or maintain an erection of the penis sufficient for satisfactory sexual performance. It has a negative impact both on the patient's quality of life and his relation with the sexual partner. ${ }^{[4]}$ In several case-controlled studies investigating the relation between AS and sexual dysfunction (SD), the prevalence of SD was higher for AS patients than normal males. ${ }^{[5]}$ However, no clear association was found between AS and erectile function. The higher ED prevalence rates in the AS population could not be demonstrated in some of the studies. ${ }^{[6,7]}$ The reasons for this discrepancy may be listed as small patient groups due to relative rare nature of the disease, differences of study designs, lack of validated questionnaires, usage of parameters, such as disease span and activity. According to current literature, several predictive factors, such as morning stiffness, disease activity and depression, have been asserted for AS patients with SD. ${ }^{[7]}$ However, the predictive factors of ED in AS patients are not still clearly elucidated. Patients' susceptibility to ED may be associated with both AS specific and related symptoms, such as depression and anxiety. The present study aims to investigate ED prevalence between healthy males and AS patients using international validated and proven questionnaires and determine the predictive factors of ED in AS patients.

\section{Methods}

This prospective case-controlled trial was conducted among patients who were presented to the physical therapy department of a teaching hospital between 2012 and 2014. Fifty males who were diagnosed as AS according to modified New York criteria and 50 healthy males were included in this study after the approval of the local ethics committee and signature of necessary consent forms (Ethic Committee no: 198/2012). The demographic data of all the subjects were recorded, and patients in both groups were similar concerning age, education and socioeconomic levels. The inclusion criteria of this study were having a sexual partner for the last three months, consenting to participate in this study while exclusion criteria were a history of pelvic surgery or radiation therapy, unregulated diabetes/hypertension and penile deformity.

The questionnaires were used to analyze ED, International Index of Erectile Function (IIEF-5), and psychology of subjects, Beck depression index (BDI) and Beck anxiety index (BAI) were completed by the subjects themselves. Bath Ankylosing Spondylitis Disease activity index (BASDAI), Bath Ankylosing Spondylitis Functional Index (BASFI), Bath Ankylosing Spondylitis Metrological Index (BASMI) and Ankylosing Spondylitis specific quality of life (ASQoL) were only answered by patients with AS.
Assessment of Clinical Parameters: In AS group, the disease activity, functional status and spinal assessment was measured via BASDAI, BASFI and BASMI respectively. ${ }^{[8-11]}$

Assessment of Quality of Life: Disease-specific quality of life was assessed using ASQoL, which included 18 questions with binary answers (yes/no). The Turkish version was validated by Duruoz et al. ${ }^{[12]}$

Assessment of Erectile functions (EF): IIEF- 5 is one of the most commonly used questionnaires for the assessment of $\mathrm{EF}$ and the validated Turkish version of it was used in our study. ${ }^{[13]}$ This questionnaire evaluates the quality of the subject's EF for the prior four weeks. The six questions were scored between 0 to 5 (Q1, Q2, Q3, Q4, Q5, Q15). Erectile dysfunction was categorized as severe ED (1-10 points), moderate ED (11-16 points), mild-moderate (17-21 points), mild ED (22-25 points) and no ED (26-30 points). ${ }^{[14]}$

Assessment of Depression and Anxiety: Beck Anxiety Inventory (BAI): $\mathrm{BAl}$ is a 21 -item self-report questionnaire with a focus on anxiety symptoms in which 13 Items are rated on a 4-point scale ranging from 0 (not at all) to 3 (severely). Validity and reliability studies of Turkish have been performed previously. ${ }^{[15]}$

Beck Depression Inventory (BDI): BDI is an instrument that assesses the presence and severity of depression and symptom levels. The 21 items of the inventory are four options Likert scale in design. Each question is scaled between 0 and 3 while the total score ranges from 0 to 63 , with the cut-off score as 17 . The Validity and reliability studies have been performed for the Turkish patients previously. ${ }^{[16]}$

\section{Statistical Analysis}

The Statistical Package of Social Sciences for Windows (SPSS) version 20 was used for statistical analysis. We divided patients into two groups based on erectile dysfunction. Categorical variables were presented as numbers and percent ages and compared with the Chi-square test. Continuous variables were presented as means and standard deviations and compared with in dependent sample t-test. Correlation analyses were evaluated using Pearson's correlation coefficient. Statistical significance was considered when a two-tailed $p$ value $<0.05$.

\section{Results}

Fifty patients with AS diagnosis and fifty healthy males were included in this study. The data of both groups can be found in Table 1. The mean ages of group 1 and 2 were $37.7 \pm 7.6$ and $37.0 \pm 6.8$, respectively, and no statistical difference was shown. Mean disease duration was determined as 10.8+9.3 years in the AS group. An erectile dysfunction of all degrees was present in 38\% (19 patients) and 30\% (15 males) of males in group 1 and 2, respectively, with no statistical difference. However mean IIEF-EF domain score of AS group (22.3 \pm 7.0$)$ was significantly lower than the control group $(25.7 \pm 4.3)(p=0.004)$ (Table 1). 
Table 1. Clinical and demographic characteristics of the patients with AS and healthy controls

\begin{tabular}{lccc}
\hline & \multicolumn{3}{c}{ Groups } \\
\cline { 2 - 4 } & AS (n=50) & Control (n=50) & $\mathbf{p}$ \\
\hline Age (years) & $37.7 \pm 7.6$ & $37.0 \pm 6.8$ & 0.648 \\
Duration of illness (years) & $10.8 \pm 9.3$ & & NA \\
AS QoL & $6.1 \pm 5.3$ & - & NA \\
BASDAI & $2.9 \pm 2.4$ & - & NA \\
BASFI & $2.9 \pm 2.5$ & - & NA \\
BASMI & $7.2 \pm 2.6$ & - & NA \\
ED 19 (38.0\%) & $15(30.0 \%)$ & 0.404 & \\
IIEF* & $22.3 \pm 7.0$ & $25.7 \pm 4.3$ & 0.004 \\
IIEF - grade & \multicolumn{3}{c}{0.189} \\
$\quad$ none & $31(62.0 \%)$ & 35 (70.0\%) \\
$\quad$ mild & $8(16.0 \%)$ & $10(20.0 \%)$ \\
$\quad$ moderate & $9(18.0 \%)$ & $4(8.0 \%)$ & \\
$\quad$ severe & $2(4.0 \%)$ & $1(2.0 \%)$ & \\
BAI* & $14.2 \pm 7.7$ & $7.4 \pm 4.5$ & 0.000 \\
BDI* & $13.9 \pm 10.9$ & $7.8 \pm 4.6$ & 0.000 \\
Beck (Above 17) & $16(32.0 \%)$ & $4(8.0 \%)$ & 0.002 \\
\hline *: Mean + standard deviation; IIEF: international index of erectile function; \\
BASDAI: bath ankylosing spondylitis disease activity index; BASFI: bath \\
ankylosing spondylitis functional index; BASMl: bath ankylosing spondylitis \\
metrological index; ASQoL: ankylosing spondylitis quality of life; ED: \\
erectile dysfunction; BDI: beck anxiety index; BAl: beck anxiety index. \\
\hline
\end{tabular}

The mean IIEF EF domain score was also lower in AS patients with ED than in the control group with ED (14.2 \pm 4.3 \& 20.9 $\pm 4.9 p=0.001)$. In addition, BDI and BAI scores were significantly higher in the AS group (Table 2). Both group's patients with ED were categorized as mild, moderate and severe in terms of ED degree. In the AS group, the number of patients with moderate or severe ED was higher than in the control group. However, this difference was not statistically significant (Table 2). AS patients were categorized into two groups according to the presence or absence of $E D$, and potential risk factors of ED were compared between two groups. The mean IIEF-EF domain of these scores these groups were $14.2 \pm 4.3$ and $27.3 \pm 1.4$, respectively. The risk factor analysis of ED in AS patients showed no difference in mean age and disease time between patients with and without ED (Table 3). BASDAI, BASFI, BDI and BAI scores were statistically higher for patients with ED. In addition, the disease-specific quality of life was lower in AS patients with ED. No significant difference in BASMI scores was demonstrated between the groups.

\section{Discussion}

AS disease causes functional and vital limitations, especially in young males, by impeding the daily routine activities of the individuals. Furthermore, a significant rate of the workforce is lost due to AS. Although the presence of a direct causality link between AS and ED is controversial, an
Table 2. AS patients with ED and Control group with ED

\begin{tabular}{|c|c|c|c|}
\hline & \multicolumn{3}{|c|}{ Groups } \\
\hline & AS $(n=19)$ & Control $(n=15)$ & $\mathbf{p}$ \\
\hline Age (years)* & $36.9 \pm 6.5$ & $36.6 \pm 4.8$ & 0.885 \\
\hline Duration of illness (years)* & $10.8 \pm 8.2$ & - & NA \\
\hline AS QoL* & $9.3 \pm 5.7$ & - & NA \\
\hline BASDAI* & $4.9 \pm 2.1$ & - & NA \\
\hline BASFI* & $4.8 \pm 2.5$ & - & NA \\
\hline BASMI* & $7.5 \pm 2.8$ & - & NA \\
\hline IIEF* & $14.2 \pm 4.3$ & $20.9 \pm 4.9$ & 0.000 \\
\hline ED - grade & & & 0.218 \\
\hline mild & $8(42.1 \%)$ & $10(66.7 \%)$ & \\
\hline moderate & $9(47.4 \%)$ & $4(26.7 \%)$ & \\
\hline severe & $2(10.5 \%)$ & $1(6.7 \%)$ & \\
\hline $\mathrm{BAI}^{*}$ & $20.7 \pm 6.8$ & $12.3 \pm 4.0$ & 0.000 \\
\hline $\mathrm{BDI}^{*}$ & $24.4 \pm 9.7$ & $12.8 \pm 3.9$ & 0.000 \\
\hline Beck (Above 17) & $15(78.9 \%)$ & $4(26.7 \%)$ & 0.002 \\
\hline \multicolumn{4}{|c|}{$\begin{array}{l}\text { *: mean + standard deviation; IIEF:International Index of Erectile Function, } \\
\text { BASDAl:Bath Ankylosing Spondylitis Disease Activity Index, BASFI: Bath } \\
\text { Ankylosing Spondylitis Functional Index, BASMI: Bath Ankylosing Spondylitis } \\
\text { Metrological Index, ASQoL: Ankylosing Spondylitis Quality of Life, ED: } \\
\text { erectile dysfunction, BDI: Beck Anxiety Index, BAI: Beck Anxiety Index. }\end{array}$} \\
\hline
\end{tabular}

Table 3. ED vs without ED in the AS patient

\begin{tabular}{|c|c|c|c|}
\hline & \multicolumn{3}{|c|}{ Groups } \\
\hline & $\operatorname{ED}(n=19)$ & Without ED $(n=31)$ & $\mathbf{p}$ \\
\hline Age (years)* & $36.9 \pm 6.5$ & $38.2 \pm 8.3$ & 0.574 \\
\hline Duration of illness (years)* & $10.8 \pm 8.2$ & $10.8 \pm 10.1$ & 0.999 \\
\hline AS QoL* & $9.3 \pm 5.8$ & $4.1 \pm 3.9$ & 0.000 \\
\hline BASDAI* & $4.8 \pm 2.1$ & $1.7 \pm 1.6$ & 0.000 \\
\hline $\mathrm{BASFI}^{*}$ & $4.8 \pm 2.5$ & $1.8 \pm 1.8$ & 0.000 \\
\hline BASMI* & $7.5 \pm 2.8$ & $7.0 \pm 2.5$ & 0.509 \\
\hline IIIEF* & $14.2 \pm 4.3$ & $27.3 \pm 1.4$ & 0.000 \\
\hline $\mathrm{BAl}^{*}$ & $20.7 \pm 6.8$ & $10.3 \pm 5.1$ & 0.000 \\
\hline $\mathrm{BDI} I^{*}$ & $24.4 \pm 9.7$ & $7.6 \pm 5.3$ & 0.000 \\
\hline Beck (Above 17) & 15 (78.9\%) & $1(3.2 \%)$ & 0.000 \\
\hline \multicolumn{4}{|c|}{$\begin{array}{l}\text { *: mean + standard deviation; IIEF:International Index of Erectile Function, } \\
\text { BASDAl:Bath Ankylosing Spondylitis Disease Activity Index, BASFI: Bath } \\
\text { Ankylosing Spondylitis Functional Index, BASMI: Bath Ankylosing Spondylitis } \\
\text { Metrological Index, ASQoL: Ankylosing Spondylitis Quality of Life, ED: } \\
\text { erectile dysfunction, BDI: Beck Anxiety Index, BAl: Beck Anxiety Index. }\end{array}$} \\
\hline
\end{tabular}

impairment of erectile functions is suggested in both active and chronic phases of AS. ${ }^{[7]}$

Diabetes, cardiovascular diseases and hypertension are the most common organic causes of ED, which may also occur as a result of psychological disturbance triggered by chronic diseases. ${ }^{[17]}$ Etiological reasons for ED in chronic rheumatoid diseases are chronic pain, fatigue, stiffness, depression, anxiety, negative body image and diminished quality of life. While the association of sexual function and 
rheumatoid disease has been investigated in the recent literature, the specific assessment of erectile functions in patients with AS is a relatively neglected topic. ${ }^{[5,7]}$

In our study, the effects of AS activity on erectile functions were investigated in 50 patients with a control group with 50 healthy males. In these two groups, which included males with similar mean ages, although the rate of ED was similar between in both groups, the IIEF-EF domain score was slightly lower in the AS group compared to the control group (22.3 \pm 7 and $25.7 \pm 4.3, p=0.004)$. A few case-controlled well-designed studies investigating sexual functions and AS were reported in the literature. IIEF questionnaire was used to assess the erectile function of 37 AS patients and 67 healthy males in the study of Bal et al. While no statistical difference of sexual function between males with and without AS was reported (35.1\% vs. $26.9 \%$ ), a significant decrease was detected in the sexual desire domain score in AS group. The authors advocated the possibility of statistical significance in case of an increased patient population. ${ }^{[6]}$ However, a significant worsening of erectile capacity was reported by Sariyildiz et al. and Pirildar et al. Similar results were published recently by Sanata et al. Forty healthy males were compared with forty patients with AS concerning ED. The mean IIEF- 5 scores of AS and control group were reported as 22 and 29, respectively $(p<0.0001) .{ }^{[18-20]}$

In a meta-analysis by Fan et al., including six studies, 340 AS patients and 337 healthy males, the erectile function of the AS patients was significantly worse than their healthy counterparts (SMD $-0.52,95 \% \mathrm{Cl}-0.68-0.37)$. In another meta-analysis by Liu et al. that included five case-controlled trials, a mean decrease of -3.07 was calculated in IIEF scores of the patients with AS. Therefore, the variance in IIEF scores between our two groups is in accordance with the literature. ${ }^{[5,7]}$ The risk factors of ED in AS patients were shown to be disease activity, time, patient age and psychic status in previous literature. In a well-designed, prospective case-controlled study, including 100 males in each group reported by Dhakad et al., ${ }^{[21]}$ a lower IIEF score $(20.48 \pm 7.14$ and 24.87 \pm 3.80 ) was found in the AS group. Furthermore, erectile function was associated with age, anxiety, depression, longer disease duration and higher BASFI score. The association of erectile function and disease activity was assessed using BASDAI, BASFI and BASMI questionnaires in our study. Spinal pain, peripheral joint stiffness, enthesis, fatigue and morning stiffness are the symptoms questioned in BASDAI questionnaires that evaluate the inflammation activity of AS. A negative correlation was detected between BASDAI, BASFI questionnaires and IIEF in AS patients with ED, whereas no such correlation could be found for the BASMI questionnaire. In a recent meta-analysis in 11 studies, a similar negative correlation between BASDAl, BASFI scores and IIEF was reported. On the other hand, morning stiffness was the only parameter related to ED in a study conducted by Pirildar et al. ${ }^{[19]}$
No significant correlation could be proven between patient age, disease duration and ED in our study. In four separate studies, no association between disease duration and ED was shown, but Dhakad et al. ${ }^{[21]}$ reported that the mean disease durations were 76 months (AS with ED) and 46 months (AS without ED) in two groups respectively. In the same study, high patient age was also suggested as a risk factor for ED. However, since AS is a disease of young males, the contribution of age for ED may be neglected. ED was associated with anxiety and depression in this study. These factors may play a vital role in ED etiology not only for patients with rheumatoid diseases but in all cases. Several studies concur with the negative role of anxiety and depression on the erectile function of AS patients. ${ }^{[18,22]}$ Shen et al. showed the association between disturbed social function impeded by depression and sexual dysfunction. ${ }^{[23]}$ Quality of life is impeded by both chronic diseases and sexual dysfunctions. The diminishment of quality of life (QoL) in patients with AS, chronic inflammatory disease, has already been established in the literature. ${ }^{[2]}$ The effects of reduced QoL on erectile function of patients with AS were investigated in our study using the AS QoL questionnaire. The QoL was shown to be even lower in AS patients with ED when compared to AS patients without ED. A negative correlation between social functions (SF-36 questionnaire) and IIEF score was reported by Bal et al. ${ }^{[6]}$ Although the association of chronic inflammatory rheumatoid diseases, such as AS and sexual functions, is well established, the direct correlation between AS and erectile functions is still debated. Erectile function scores were slightly lower in the AS group than the control group in our study. ED risk factors were shown as disease activity and psychological status. The practitioners in this field should be aware of ED and refer the patients to urologists if needed.

\section{Disclosures}

Ethics Committee Approval: Ethics Committee of Istanbul Training and Research Hospital (decision no: 198, date: 19.10.2012).

Peer-review: Externally peer-reviewed.

Conflict of Interest: None declared.

Authorship Contributions: Concept - I.H.E.; Design - I.H.E., M.O.; Supervision - I.H.E.; Materials - I.H.E., M.O., E.S.; Data collection \&/ or processing - I.H.E., M.O., E.S.; Analysis and/or interpretation E.S.; Literature search - I.H.E., E.S.; Writing - I.H.E., E.S., M.O.; Critical review - I.H.E., M.O., E.S.

\section{References}

1. Strand V, Rao SA, Shillington AC, Cifaldi MA, McGuire M, Ruderman EM. Prevalence of axial spondyloarthritis in United States rheumatology practices: Assessment of SpondyloArthritis International Society criteria versus rheumatology expert clinical diagnosis. Arthritis Care Res (Hoboken) 2013;65:1299-306. [CrossRef]

2. Braun J, Sieper J. Ankylosing spondylitis. Lancet 2007;369:1379-90. 
3. Tristano AG. The impact of rheumatic diseases on sexual function. Rheumatol Int 2009;29:853-60. [CrossRef]

4. Wespes E, Amar E, Hatzichristou D, Hatzimouratidis K, Montorsi F, Pryor J, et al; EAU. EAU Guidelines on erectile dysfunction: an update. Eur Urol 2006;49:806-15. [CrossRef]

5. Liu YF, Dong H, Chen Z, Wang YU, Tu SH. Impact of ankylosing spondylitis on sexual function: A systematic review and metaanalysis. Exp Ther Med 2015;9:1501-7. [CrossRef]

6. Bal S, Bal K, Turan Y, Deniz G, Gürgan A, Berkit IK, Sendur OF. Sexual functions in ankylosing spondylitis. Rheumatol Int 2011;31:88994. [CrossRef]

7. Fan D, Liu L, Ding N, Liu S, Hu Y, Cai G, et al. Male sexual dysfunction and ankylosing spondylitis: a systematic review and metaanalysis. J Rheumatol 2015;42:252-7. [CrossRef]

8. Akkoc Y, Karatepe AG, Akar S, Kirazli Y, Akkoc N. A Turkish version of the Bath Ankylosing Spondylitis Disease Activity Index: reliability and validity. Rheumatol Int 2005;25:280-4. [CrossRef]

9. Calin A, Garrett S, Whitelock H, Kennedy LG, O'Hea J, Mallorie P, et al. A new approach to defining functional ability in ankylosing spondylitis: the development of the Bath Ankylosing Spondylitis Functional Index. J Rheumatol 1994;21:2281-5.

10. Jenkinson TR, Mallorie PA, Whitelock HC, Kennedy LG, Garrett SL, Calin A. Defining spinal mobility in ankylosing spondylitis (AS). The Bath AS Metrology Index. J Rheumatol 1994;21:1694-8.

11. Karatepe AG, Akkoc Y, Akar S, Kirazli Y, Akkoc N. The Turkish versions of the Bath Ankylosing Spondylitis and Dougados Functional Indices: reliability and validity. Rheumatol Int 2005;25:612-8.

12. Duruöz MT, Doward L, Turan Y, Cerrahoglu L, Yurtkuran M, Calis $M$, et al. Translation and validation of the Turkish version of the Ankylosing Spondylitis Quality of Life (ASQOL) questionnaire. Rheumatol Int 2013;33:2717-22. [CrossRef]

13. Turunç T, Deveci S, Güvel S, Peşkircioğlu L. The assessment of Turkish validation with 5 question version of International Index of Erectile Function (IIEF-5). Turk J Urol 2007;33:45-9.
14. Rosen RC, Riley A, Wagner G, Osterloh IH, Kirkpatrick J, Mishra A. The international index of erectile function (IIEF): a multidimensional scale for assessment of erectile dysfunction. Urology 1997;49:822-30. [CrossRef]

15. Ulusoy M, Hisli Sahin N, Erkmen H. Turkish Version of the Beck Anxiety Inventory: Psychometric Properties. Journal of Cognitive Psychotherapy 1998;12.

16. Aydemir O, Guvenir T, Kuey L, Kultur S. Validity and reliability of Turkish version of hospital anxiety and depression scale. Turk Psikiyatri Derg 1997;8:280-7.

17. Hatzimouratidis K, Amar E, Eardley I, Giuliano F, Hatzichristou D, Montorsi F, et al; European Association of Urology. Guidelines on male sexual dysfunction: erectile dysfunction and premature ejaculation. Eur Urol 2010;57:804-14. [CrossRef]

18. Sariyildiz MA, Batmaz I, Dilek B, Inanir A, Bez Y, Tahtasiz M, et al. Relationship of the sexual functions with the clinical parameters, radiological scores and the quality of life in male patients with ankylosing spondylitis. Rheumatol Int 2013;33:623-9. [CrossRef]

19. Pirildar T, Müezzinoğlu T, Pirildar S. Sexual function in ankylosing spondylitis: a study of 65 men. J Urol 2004;171:1598-600. [CrossRef]

20. Santana T, Skare T, Delboni VS, Simione J, Campos APB, Nisihara R. Erectile dysfunction in ankylosing spondylitis patients. Int Braz J Urol 2017;43:730-5. [CrossRef]

21. Dhakad U, Singh BP, Das SK, Wakhlu A, Kumar P, Srivastava D, et al. Sexual dysfunctions and lower urinary tract symptoms in ankylosing spondylitis. Int J Rheum Dis 2015;18:866-72. [CrossRef]

22. Ozgül A, Peker F, Taskaynatan MA, Tan AK, Dinçer K, Kalyon TA. Effect of ankylosing spondylitis on health-related quality of life and different aspects of social life in young patients. Clin Rheumatol 2006;25:168-74. [CrossRef]

23. Shen B, Zhang A, Liu J, Da Z, Xu X, Gu Z. A primary analysis of sexual problems in Chinese patients with ankylosing spondylitis. Rheumatol Int 2013;33:1429-35. [CrossRef] 